\title{
Absorption of Cholesterol from a Micellar Solution: Intestinal Perfusion Studies in Man*
}

\author{
Wilfred J. Simmonds, $\uparrow$ Alan F. Hofmann, $\ddagger$ and Emanuel Theodor $\S$ \\ (From the Hospital of the Rockefeller University, New York, N. Y.)
}

Summary. The absorption of cholesterol has been studied in man by perfusing the upper jejunum with a micellar solution of bile salt, 1-monoglyceride, and cholesterol- ${ }^{14} \mathrm{C}$, with a triple lumen tube with collection sites $50 \mathrm{~cm}$ apart. The absorption of micellar components between the collection sites was calculated from their concentration changes relative to those of the watersoluble marker, polyethylene glycol. Control experiments were performed with cholesterol-free perfusions of saline or bile salt-monoglyceride solutions. Steady state conditions were obtained.

Each of the components of the micelle was absorbed to a different extent during passage through the test segment of jejunum. Bile salt was not absorbed (mean, $-3 \%$ ), but micellar monoglyceride was rapidly hydrolyzed and absorbed almost completely (mean, 98\%). Cholesterol radioactivity was absorbed to an intermediate extent (mean, $73 \%$ ), and the absorption of chemically determined cholesterol (mean, 46\%) indicated that much of the disappearance of radioactivity represented true absorption and not simple exchange.

The specific activity of the perfused cholesterol fell during passage through the loop. This fall was interpreted as signifying the continuous addition of nonradioactive endogenous cholesterol by the test segment. However, the decrease in specific activity may also be considered to signify exchange, in that nonradioactive molecules entered the lumen as radioactive molecules were absorbed. Plant sterols appeared in the intestinal contents during the perfusion and must have been contributed by the perfused segment.

The perfusate and samples taken from the upper and lower collection sites were examined by ultracentrifugation to define the physical state of cholesterol. It was found that cholesterol in the perfusate or upper collection site samples did not sediment, but that $23 \%$ of the cholesterol in the lower collection site samples was sedimentable (mean of three experiments); bile salt, as control, was not sedimentable. Solubility experiments in model systems showed that cholesterol possessed low solubility in bile salt solution; its solubility increased markedly and in linear proportion to the amount of

* Submitted for publication October 3, 1966; accepted February 2, 1967.

This study was supported by U. S. Public Health Service grant HE-06222, National Heart Institute, to Professor E. H. Ahrens, Jr., and in part by U. S. Public Health Service grant FR-00102 from the General Clinical Research Centers Branch of the Division of Research Facilities and Resources.

Presented in part before the Gastroenterology Sectional Meeting of the American Federation for Clinical Research on May 1, 1966, and published in abstract form (1).
†Commonwealth Fund Fellow. Present address: University of Western Australia, Nedlands, Australia. $¥$ Address requests for reprints to Dr. Alan F. Hofmann, Gastroenterology Unit, Mayo Clinic and Mayo Foundation, Rochester, Minn. 55901.

$\S$ Postdoctoral trainee, Dept. of Medicine, Cornell University Medical College, under U. S. Public Health Service grant TI AM 5430, National Institute of Arthritis and Metabolic Diseases, and fellow of the John A. Hartford Foundation. Present address: Tel-Hashomer Government Hospital, Tel-Aviv, Israel. 
fatty acid or monoglyceride or both that was added to the bile salt solution. These findings suggest that polar lipid such as fatty acid or monoglyceride as well as bile salt is essential for normal micellar solubilization of cholesterol in intestinal content. They suggest the necessity of considering an insoluble sedimentable phase of particulate sterol in intestinal content as well as an oil and micellar phase for a complete description of sterol absorption.

The marked difference in the rates of absorption of individual micellar components suggests that micellar lipid is not absorbed as an intact aggregate and is consistent with the view that polar lipid such as fatty acid is absorbed in molecular form by diffusion from a micellar solution. The experiments confirm previous findings demonstrating that fat absorption without bile salt absorption occurs in the upper small intestine in man.

\section{Introduction}

A micellar solution of bile salt, fatty acid, monoglyceride, and cholesterol is present in intestinal contents during digestion in man, and it has been proposed that both fat and cholesterol are absorbed from such a micellar dispersion (2-5). This paper describes the preparation of a micellar solution of bile salt, monoglyceride, and cholesterol simulating that normally present in the human intestinal lumen and the results obtained when such a solution was perfused through a $50-\mathrm{cm}$ segment of healthy jejunum in order to study cholesterol absorption under steady state conditions in unanesthetized man.

An isotonic micellar solution of bile salt, 1-monoglyceride, and cholesterol-14 $\mathrm{C}$ containing the nonabsorbable reference material polyethylene glycol (PEG) was prepared and perfused through a nasojejunal triple lumen tube (6). The absorption of each micellar component relative to that of PEG was determined. The perfusion studies were supplemented by in vitro experiments, in which the effect of added polar lipid (monoglyceride or fatty acid or both) on cholesterol solubility in bile salt solution was examined, and further, by ultracentrifugal examination of the physical state of cholesterol in samples of intestinal contents before and after exposure to the absorbing surface of the jejunal test segment.

\section{Methods}

I) Perfusion EXPERIMENTS

\section{A) Experimental design}

Continuous perfusion of a single solution or sequential perfusions of different solutions were carried out. The composition of the perfusates is indicated by letter abbreviations $\left(C=\right.$ cholesterol- $4-{ }^{14} \mathrm{C} ; \mathrm{M}=$ micellar bile saltmonoglyceride; and $\mathrm{S}=$ saline), with arabic subscripts denoting specific experiments.

In experiments $\mathrm{MC}_{1}, \mathrm{MC}_{2}$, and $\mathrm{MC}_{3}$, radioactive cholesterol in micellar bile salt-monoglyceride was perfused. Perfusates in all other experiments did not contain cholesterol. In experiment $M$, the perfusate was micellar bile salt-monoglyceride; and in experiment $\mathrm{S}$, saline. In experiments $S \rightarrow M_{1}$ and $S \rightarrow M_{2}$, saline was perfused first, then micellar bile salt-monoglyceride. In experiments $M \rightarrow S_{1}$ and $M \rightarrow S_{2}$, the order of the perfusions was reversed, with the first perfusate being micellar bile salt-monoglyceride. In two experiments, the 1-monoglyceride contained $0.8 \mu \mathrm{c}$ of glyceryl-1-monooleate-1-14C.

\section{B) Experimental subjects}

Subjects were free of symptoms or signs of gastrointestinal disease; the data relevant to their clinical diagnoses and the experiments performed on each subject are shown in Table I.

\section{C) Composition and preparation of perfusates}

1) Materials. a) Bile salts. For Subjects 2, 4, and 5, synthetic taurocholate $(7,8)$ and taurodeoxycholate 1 were used; both conjugated bile salts were pure by thin layer chromatography (9) except for traces of free bile acid, which by potentiometric determination (10), was less than $4 \%$ of the total bile acid present. In Subjects 1 and 3 , a mixture of conjugated bile salts was isolated from a commercially available preparation of iron bile salts ${ }^{2}$ by passing a filtered ethanolic solution over a cation exchange resin column $\left(\mathrm{H}^{+}\right.$form) and neutralizing the effluent. After further purification by solvent extraction, a product was obtained, which by thin layer chromatography was a mixture of taurine and glycine

\footnotetext{
1 Maybridge Chemical Co., Ferny Park, Rocky Valley, Tintagel, Cornwall, England.

2 Bilron, Lilly Research Laboratories, Indianapolis, Ind.
} 
TABLE I

Experimental subjects

\begin{tabular}{|c|c|c|c|c|c|}
\hline $\begin{array}{c}\text { Sub- } \\
\text { ject }\end{array}$ & $\begin{array}{l}\text { Age and } \\
\text { sex }\end{array}$ & Clinical history & Laboratory findings & Drug regimen and diet & $\begin{array}{l}\text { Experiment date } \\
\text { and type* }\end{array}$ \\
\hline 1 & $57 \mathrm{M}$ & $\begin{array}{l}\text { Hypercholesterolemia, } \\
\text { arteriosclerotic heart disease; } \\
\text { myocardial infarction, 1959; } \\
\text { angina pectoris. }\end{array}$ & $\begin{array}{l}\quad m g / 100 m l \\
\text { Cholesterol, } 232 \\
\text { Phospholipid, } 243 \\
\text { Triglyceride, } 124\end{array}$ & $\begin{array}{l}\text { Chlorphenoxyisobutyrate, } \\
2.0 \mathrm{~g} / \text { day. Vegetable fat. }\end{array}$ & $\begin{array}{l}7-20, S \rightarrow M_{1} \\
7-21, M \rightarrow S_{1}\end{array}$ \\
\hline 2 & $38 \mathrm{M}$ & $\begin{array}{l}\text { Familial hypercholesterolemia } \\
\text { with xanthomatosis; no } \\
\text { evidence of cardiovascular } \\
\text { disease. }\end{array}$ & $\begin{array}{l}\text { Cholesterol, } 240 \\
\text { Phospholipid, } 288 \\
\text { Triglyceride, } 319\end{array}$ & $\begin{array}{l}\text { Chlorphenoxyisobutyrate, } \\
2.0 \mathrm{~g} / \text { day. Vegetable fat. }\end{array}$ & $\begin{array}{l}8-30, \mathrm{M} \\
9-1, \mathrm{MC}_{1}\end{array}$ \\
\hline 3 & $50 \mathrm{~F}$ & $\begin{array}{l}\text { Hypertensive cardiovascular } \\
\text { disease; angina pectoris. }\end{array}$ & Cholesterol, 213 & None. Normal. & $\begin{array}{l}7-29, \mathrm{M} \rightarrow \mathrm{S}_{2} \\
7-30, \mathrm{~S} \rightarrow \mathrm{M}_{2}\end{array}$ \\
\hline 4 & $45 \mathrm{M}$ & $\begin{array}{l}\text { Carbohydrate-induced hyper- } \\
\text { glyceridemia; xanthomatosis; } \\
\text { peripheral vascular disease. }\end{array}$ & $\begin{array}{l}\text { Cholesterol, } 774 \\
\text { Phospholipid, } 615 \\
\text { Triglyceride, } 1,082\end{array}$ & $\begin{array}{l}\text { Bishydroxycoumarin, } \\
\text { chlorphenoxyisobutyrate, } \\
2.0 \mathrm{~g} / \text { day. Vegetable } \\
\text { fat, low carbohydrate. }\end{array}$ & $9-16, \mathrm{MC}_{3}$ \\
\hline 5 & $61 \mathrm{M}$ & Angina pectoris. & $\begin{array}{l}\text { Cholesterol, } 234 \\
\text { Phospholipid, } 221 \\
\text { Triglyceride, } 195\end{array}$ & None. Vegetable fat. & $\begin{array}{l}9-21, \mathrm{MC}_{2} \\
9-22, \mathrm{~S}\end{array}$ \\
\hline
\end{tabular}

* $\mathrm{S}=$ saline, $\mathrm{M}=$ micellar bile salt-monoglyceride, and $\mathrm{C}=$ cholesterol-4-14 $\mathrm{C} ;$ arabic subscripts denote specific experiments.

conjugates and contained neither free bile acids, appreciable pigments, iron, nor phospholipid.

b) Cholic acid. Cholic acid- $24-{ }^{14} \mathrm{C}^{3}$ was purified by ion exchange chromatography (11) and thin layer chromatography (9) before use. Sodium taurocholate-24- ${ }^{14} \mathrm{C}$ was prepared as described above $(7,8)$.

c) Monoglyceride. A commercial preparation of glyceryl-1-mono-oleate 4 was used (12); it contained traces of diglyceride and 7 to $15 \%$ free fatty acid by titration. Glycerol-1-mono-oleate-1-1" $\mathrm{C}$ was synthesized from glyceryl-trioleate- $1-{ }^{14} \mathrm{C}^{5}$ by glycerolysis (13) and then purified by preparative thin layer chromatography.

d) Cholesterol. Cholesterol-4- ${ }^{14} \mathrm{C}$ (purified by preparative thin layer chromatography) was cocrystallized from absolute ethanol with nonradioactive cholesterol (pure by gas-liquid chromatography) before its addition to the perfusate (14).

2) Composition of perfusates. All perfusates were isotonic and contained 0.5 or $1.0 \mathrm{~g}$ per $100 \mathrm{ml} \mathrm{PEG.6}$ The bile salt monoglyceride-cholesterol perfusates had the following composition in $\mathrm{g}$ per $100 \mathrm{ml}$ perfusate: sodium taurocholate, $0.5(7 \mathrm{mM})$; sodium taurodeoxycholate, 0.16 (3 $\mathrm{mM}$ ) ; 1-monoglyceride, 0.25 (7 $\mathrm{mM}$ ); and cholesterol-4- ${ }^{14} \mathrm{C}, 0.01(0.26 \mathrm{mM})$. The perfusate in experiment $M$ contained no cholesterol, but was otherwise identical. The bile salt monoglyceride perfusates

${ }^{3}$ Nuclear Research Chemicals, Orlando, Fla.

- Mono-olein (technical), Distillation Products Industries, Rochester, N. Y. This material is now marketed under the name Myverol, distilled monoglycerides, type 18-71E.

5 Volk Radiochemical Co., Chicago, Ill.

6 Rugar Chemical Co., Irvington-on-Hudson, N. Y. of the crossover experiments had $0.8 \mathrm{~g}$ (about $16 \mathrm{mmoles}$ ) of mixed crystalline bile salt conjugates per $100 \mathrm{ml}$ perfusate and $0.5 \mathrm{~g} \mathrm{1-monoglyceride} \mathrm{per} 100 \mathrm{ml}$ perfusate.

3) Preparation of perfusates. The required amounts of bile salts, mono-olein, cholesterol, and PEG were added to about three-fourths of the final volume of the sodium chloride solution in a flask that was stoppered and stirred magnetically at $37^{\circ}$ overnight. The solution was then either clear or contained a few suspended cholesterol crystals. After addition of the remaining sodium chloride solution and further stirring, the mixture was filtered through fine filter paper ${ }^{7}$ on a Buchner funnel. The filtrate was a water clear, micellar solution (12, 15-17); neither radioactivity nor chemically determined cholesterol was removed by passage through a $50-\mathrm{m} \mu$ Millipore filter ${ }^{8}$ or by ultracentrifugation; see below.

\section{D) Perfusion procedure}

1) Construction of tube. A triple lumen tube similar to that described by Cooper, Levitan, Fordtran, and Ingelfinger (6) was constructed from polyvinyl chloride tubing, o.d. $1.5 \mathrm{~mm} .^{9}$ Tube 1 was $10 \mathrm{~cm}$ shorter than tube 2, which in turn was $50 \mathrm{~cm}$ shorter than tube 3 . Samples of intestinal contents passing the upper collection site (end of tube 2) and lower collection site (end of tube 3) were aspirated continuously.

2) Intubation and labeling of the subject's bile salt pool. The tube was passed transnasally on the day preceding the first perfusion study. During the afternoon,

7 No. 576, Schleicher and Schuell, Keene, N. H.

8 Millipore Filter Corp., Bedford, Mass.

9 Pharmaseal Laboratories, Glendale, Calif. 
subjects were given cholic $\operatorname{acid}-{ }^{14} \mathrm{C}$, either as sodium taurocholate-24- ${ }^{14} \mathrm{C}$ or sodium cholate- $24-{ }^{14} \mathrm{C}$ intravenously. Equilibration of the label with the patient's bile acid pool occurred during digestion of the evening meal (18).

The tube was allowed to progress to the desired location during the night. On the following morning, the location of the tube was confirmed by $\mathrm{X}$ ray after the injection of water-soluble contrast material. The distance from the nose to the tube openings was the same in all experiments (in $\mathrm{cm}$ from the nose): infusion site, 100 $\mathrm{cm}$; upper collection site, $110 \mathrm{~cm}$; and lower collection site, $160 \mathrm{~cm}$. The $50-\mathrm{cm}$ test segment was in the proximal jejunum (19).

3) Perfusion. Fluid was infused by a roller pump for a period of 4 hours at $400 \mathrm{ml}$ per hour in all experiments except those of crossover design in which the perfusion rate was $200 \mathrm{ml}$ per hour. The perfusate was stirred magnetically and pumped from a graduated reservoir at $37^{\circ} \mathrm{C}$. Intestinal contents were collected by siphonage, into flasks immersed in an acetone-dry ice bath; 30 -minute collections were used. The test segment was perfused for 30 minutes before collections were begun. The first samples to be analyzed were taken from the upper collection site at $\frac{1}{2}$ to 1 hour, and from the lower collection site at 1 to $1 \frac{1}{2}$ hours. Samples were stored at $-18^{\circ} \mathrm{C}$.

When the perfusion was finished, the transit time of the perfusate through the test segment was determined by injection of Evans blue dye from the perfusion site. The rate of appearance of dye at the upper and lower collection sites was determined spectrophotometrically. The tube was then withdrawn about $60 \mathrm{~cm}$ so that its distal end remained in the distal duodenum. Cholecystokinin ${ }^{10}$ was injected intravenously, and 1 to $2 \mathrm{ml}$ of bile was removed for analysis. The tubing was allowed to progress during the night to its previous position in the upper jejunum. On the following morning, after $\mathrm{X}$-ray confirmation of the location, a second perfusion was carried out.

4) Transit time. Measurements of PEG concentrations indicated that the perfusate passed from the upper collection site to the lower collection site in 30 to $60 \mathrm{~min}$ utes. Emptying of the gallbladder was evidenced by abrupt changes in bile pigment concentrations of samples from the upper collection site; these changes were followed by similar but less striking changes in samples from the lower collection site during the subsequent $\frac{1}{2}$ to 1 hour. These estimates were confirmed by the results of the dye injections.

E) Ultracentrifugal examination of the physical state of cholesterol in samples of intestinal content and perfusate

Samples $(12 \mathrm{ml})$ of intestinal contents were collected from the upper and lower collection sites during the continuous perfusion of micellar cholesterol $\left(\mathrm{MC}_{1}, \mathrm{MC}_{2}\right.$, and $\mathrm{MC}_{3}$ ). These samples as well as the perfusates were heated at $70^{\circ} \mathrm{C}$ for 10 minutes immediately after collection to inactivate pancreatic lipase (4). They were then

${ }^{10}$ Cecekin, Vitrum, Stockholm, Sweden. spun at $100,000 \times g$ for 4 hours in a Spinco model L preparative ultracentrifuge in a no. 40 rotor at 40 to $42^{\circ} \mathrm{C}$ (4). Each tube was cut in half with a tube slicer, and a measured sample of supernate was aspirated with a syringe. The sediment on the bottom of the tube was then thoroughly suspended in the infranate, and the mixture was quantitatively aspirated and its volume recorded. Mass analyses were made of bile acids, cholesterol, fatty acid, and monoglyceride (see below); radioactivity of bile acids and cholesterol fractions also was measured.

In calculating the percentage of bile acid or cholesterol that was "sedimentable," we assumed that the supernate (s) was micellar, and that the infranate (i) was micellar but in addition contained a sediment of negligible

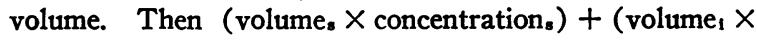
concentration $\left._{1}\right)=$ total bile acid (or cholesterol). Then total $-\left(\right.$ volume $_{\text {total }} \times$ concentration $\left._{\mathrm{s}}\right)=$ amount sediment $^{-}$ able, and per cent sedimentable = amount sedimentable/ total $\times 100$.

\section{F) Analytical procedures}

Samples stored at $-18^{\circ} \mathrm{C}$ for various times up to 30 days were rapidly thawed and held at $70^{\circ}$ to $80^{\circ}$ for 10 minutes to inactivate pancreatic lipase. They were then replaced in storage at $+4^{\circ} \mathrm{C}$, and all analyses were completed within 1 week from the time of thawing.

PEG was measured by the turbidometric method of Hydén (20). Sterols, glycerides, and fatty acids were extracted as described previously $(11,21)$, and the pooled extracts were evaporated and taken up to a fixed volume. Samples were taken for fatty acid titration $(0.02 \mathrm{~N}$ $\mathrm{NaOH}$, thymol blue, nitrogen stream), periodate determination of monoglyceride (22), and measurement of radioactivity.

Sterols were determined by gas-liquid chromatography as described by Miettinen, Ahrens, and Grundy (14). Bile acids were measured by gas-liquid chromatography, according to Grundy, Ahrens, and Miettinen (23), or, in experiments in which micellar cholesterol was continuously infused, were determined by titration. A 2.0 $\mathrm{ml}$ sample was buffered to $\mathrm{pH} 5$ with $1.0 \mathrm{ml}$ of $0.5 \mathrm{M}$ $\mathrm{NaH}_{2} \mathrm{PO}_{4}$, and the sterols, glycerides, and fatty acids were removed by extraction as previously described $(11,21)$. The lower phase was evaporated to dryness and saponified (23). After acidification and extraction, the hydrolyzed bile acids were dissolved in $2 \mathrm{ml}$ ethanol and titrated with $0.02 \mathrm{~N} \mathrm{NaOH}$, together with appropriate blanks and standards.

Densities of samples of intestinal content were determined pycnometrically, with $10.0-\mathrm{ml}$ volumetric flasks calibrated at $37^{\circ} \mathrm{C}$.

Radioactivity was determined by liquid scintillation detection with a Packard spectrometer as previously described $(14,23)$, with toluene for radioactive sterols and monoglycerides, and dioxane for bile acids, as described by Bray (24).

For preparative thin layer chromatography, samples were applied to glass plates prepared with silica gel $G^{11}$

11 Brinkmann Instruments, Westbury, N. Y. 
and chromatographed with appropriate solvent systems (25). After detection with iodine vapor or a rhodamine 6G spray, compounds were eluted with a suction-filtration apparatus (26).

\section{II) Cholesterol solubility studies}

Studies were performed to measure the influence of added polar lipid (oleic acid or glyceryl-1-mono-oleate or both) on cholesterol solubility in bile salt solution. In these experiments, the concentration of bile salt was well above its critical micellar concentration, and the amount of added fatty acid or monoglyceride was sufficiently small that the solutions to be equilibrated with the excess cholesterol were clear $(12,21)$. After equilibration with an excess of crystalline cholesterol of known specific activity, the solution was filtered, and the amount of dissolved cholesterol was obtained by dividing the radioactivity concentration by the specific activity of the incubated cholesterol $(21,27)$.

A solution of sodium taurocholate and sodium taurodeoxycholate (total bile acid concentration, 10 mmoles per L), corresponding to that used in the cholesterolcontaining perfusates, was prepared. Varying ratios of glyceryl-1-mono-oleate to oleic acid were added to achieve the following total concentrations in the final micellar solution: $0.2,1,2$, and 4 mmoles per L. Oleic acid ${ }^{12}(98 \%$ purity by gas-liquid chromatography), glyceryl-1-monooleate ${ }^{13}$ (at least $95 \%$ purity in class and homologue composition), and cholesterol-2-4- ${ }^{8} \mathrm{H}$ (purified by preparative thin layer chromatography) of known specific activity were added from heptane solution to ampules; solvent was removed by evaporation. The calculated amount of $0.02 \mathrm{~N} \mathrm{NaOH}$ in $0.13 \mathrm{M} \mathrm{NaCl}$ was added to neutralize fatty acid, followed by an appropriate volume of $0.15 \mathrm{M} \mathrm{NaCl}$ to make $1.0 \mathrm{ml}$. Finally, phosphate buffer and sodium taurocholate-sodium taurodeoxycholate were added to a total volume of $5.0 \mathrm{ml}$. All solutions were 0.15 mole per $\mathrm{L}$ in total $\mathrm{Na}^{+}$concentration, and experiments were conducted at $\mathrm{pH} 6.5$ and $\mathrm{pH} 7.0$ to determine the influence of fatty acid ionization on cholesterol solubility (28). The ampules were fused, shaken for 1 week at $37^{\circ} \mathrm{C}$, and their contents filtered through a $50-\mathrm{m} \mu$ Millipore filter.

\section{III) Statistical tReatment of DATA ANd Calculations}

Student's $t$ test (29) was used, after probit plots of the ranked data $(30)$ had indicated that they were normally distributed.

\section{A) Concentration}

Changes in per cent concentration relative to the perfusate are defined as [ (mass of component per milligram PEG) sample] / [ (mass of component per milligram PEG) perfusate] $\times 100$.

12 Hormel Institute, Austin, Minn.

13 Generously provided by Dr. Fred Mattson, Procter and Gamble Co., Cincinnati, Ohio.

\section{B) Balance calculations}

The mass of PEG passing through the segment ( $\mathrm{PEG}_{\text {seg }}$ ) equals the PEG perfused minus the PEG removed by sampling from the upper collection site. Therefore, for the test segment, input $=P E_{\text {seg }} \times$ (milligrams component per milligram $P E G_{u p p e r}$ ), and output $=\mathrm{PEG}_{\mathrm{s} \bullet \mathrm{g}} \times$ (milligrams component per milligram $\mathrm{PEG}_{\text {1ower }}$ ). Absorption or excretion (in per cent ) = [ (input - output)/input] $\times 100$. A representative set of balance calculations for one experiment is shown in Table II.

\section{C) Calculation of per cent absorption}

In the calculation of per cent absorption, any erroneously low input figure causes misleadingly high absorption data. To calculate meaningful absorption figures that may be compared, we pooled the data as follows : for bile salt radioactivity, by patient ( $n=5,38$ collections); for monoglyceride radioactivity, by individual collections $(\mathrm{n}=7)$; for monoglyceride mass, by individual collections $(n=6)$; for cholesterol radioactivity, by individual collections $(n=15)$; for cholesterol mass, by pooled collection intervals ( $n=6,15$ collections); and for apparent endogenous cholesterol mass, by patient $(n=3$, 17 collections). Because of the variation in input in the data pools, no meaningful statistical expression of the dispersion of the data is possible, nor may conventional tests of statistical significance be employed.

\section{D) Bile acid}

The bile acid balances for individual periods showed large figures for absorption or secretion, but were normally distributed with a mean of 0 and an SE of 9 for a mean input of $97 \mathrm{dpm}$ per period. It was considered reasonable to regard these fluctuations as sampling error associated with the relatively short collection periods (6). Therefore, all inputs and all outputs for a given period were averaged in calculating absorption. Since the radioactivity of endogenous bile acids of the five subjects varied considerably, both arithmetic and geometric normalization procedures were carried out. The results of these mathematical treatments were similar.

\section{E) Monoglyceride}

The ranged differences of output from input were normally distributed for both radioactivity and mass, although the number of periods was small ( 7 for radioactivity; 5 for mass).

\section{F) Cholesterol}

Cholesterol radioactivity was measured directly; cholesterol mass was determined by gas-liquid chromatography and considered to be the sum of perfused and endogenous cholesterol. The mass of perfused cholesterol was calculated by dividing radioactivity by the specific activity of perfused cholesterol. The difference between the mass of total cholesterol (determined by gas-liquid chromatography) and the mass of perfused cholesterol (calcu- 
TABLE II

Typical balance calculation (experiment $M C_{1}$ )

\begin{tabular}{|c|c|c|c|c|c|c|c|c|}
\hline \multicolumn{2}{|l|}{ Component } & $\frac{1}{3-1} \mathrm{hr}$ & $1-1 \frac{1}{h r}$ & $1+2 \mathrm{hr}$ & $2-2 \mathrm{hr}$ & $2 \mathrm{t}-3 \mathrm{hr}$ & Total & $\begin{array}{l}\text { Change* } \\
\text { Absorp- } \\
\text { tion ( }) \\
\text { or excre- } \\
\text { tion }(-)\end{array}$ \\
\hline PEG $†$ through segment, $m g$ & & 1,006 & 940 & 985 & 954 & 1,000 & & $\%$ \\
\hline $\begin{array}{l}\text { Perfused micellar cholesterol-14 } \mathrm{C} \text {, } \\
\qquad d p m \times 10^{3}\end{array}$ & $\begin{array}{l}\text { In } \\
\text { Out }\end{array}$ & $\begin{array}{l}262 \\
104\end{array}$ & $\begin{array}{r}265 \\
79\end{array}$ & $\begin{array}{r}248 \\
72\end{array}$ & $\begin{array}{r}263 \\
90\end{array}$ & $\begin{array}{l}324 \\
144\end{array}$ & $\begin{array}{r}1,362 \\
489\end{array}$ & \\
\hline Apparent absorption & & 158 & 186 & 176 & 173 & 180 & 873 & 64 \\
\hline Cholesterol mass, $m g$ & $\begin{array}{l}\text { In } \\
\text { Out }\end{array}$ & $\begin{array}{l}26.0 \\
14.3\end{array}$ & $\begin{array}{r}14.3 \\
9.0\end{array}$ & $\begin{array}{r}16.4 \\
7.6\end{array}$ & $\begin{array}{l}14.2 \\
12.3\end{array}$ & $\begin{array}{l}31.8 \\
22.8\end{array}$ & $\begin{array}{r}102.7 \\
66.0\end{array}$ & \\
\hline Apparent absorption & & 11.7 & 5.3 & 8.8 & 1.9 & 9.0 & 36.7 & 36 \\
\hline $\begin{array}{l}\text { Apparent endogenous } \\
\text { cholesterol, } m g\end{array}$ & $\begin{array}{l}\text { In } \\
\text { Out }\end{array}$ & $\begin{array}{r}14.2 \\
9.5\end{array}$ & $\begin{array}{l}2.3 \\
5.5\end{array}$ & $\begin{array}{l}5.1 \\
4.3\end{array}$ & $\begin{array}{l}2.4 \\
8.3\end{array}$ & $\begin{array}{l}17.2 \\
16.3\end{array}$ & $\begin{array}{l}41.2 \\
43.9\end{array}$ & \\
\hline Apparent absorption & & 4.7 & & 0.8 & & 0.9 & & -7 \\
\hline Apparent excretion & & & 3.2 & & 5.9 & & 2.7 & \\
\hline $\begin{array}{l}\text { Bile acid radioactivity, } \\
\qquad d p m \times 10^{3}\end{array}$ & $\begin{array}{l}\text { In } \\
\text { Out }\end{array}$ & $\begin{array}{l}339 \\
276\end{array}$ & $\begin{array}{l}55 \\
96\end{array}$ & $\begin{array}{r}115 \\
64\end{array}$ & $\begin{array}{r}15 \\
111\end{array}$ & $\begin{array}{l}218 \\
308\end{array}$ & $\begin{array}{l}742 \\
855\end{array}$ & \\
\hline Apparent absorption & & 63 & & 51 & & & & \\
\hline Apparent excretion & & & 51 & & 96 & 90 & 113 & -15 \\
\hline Bile acid mass, $m E q$ & $\begin{array}{l}\text { In } \\
\text { Out }\end{array}$ & $\begin{array}{l}1.97 \\
1.73\end{array}$ & $\begin{array}{l}1.51 \\
1.44\end{array}$ & $\begin{array}{l}1.61 \\
1.45\end{array}$ & & . & $\begin{array}{l}5.08 \\
4.62\end{array}$ & \\
\hline Apparent absorption & & 0.24 & 0.07 & 0.16 & & & 0.47 & 9 \\
\hline Plant sterols, $m g$ & $\begin{array}{l}\text { In } \\
\text { Out }\end{array}$ & $\begin{array}{l}0.45 \\
0.44\end{array}$ & $\begin{array}{l}0.21 \\
0.27\end{array}$ & $\begin{array}{l}0.24 \\
0.26\end{array}$ & $\begin{array}{l}0.13 \\
0.31\end{array}$ & $\begin{array}{l}0.40 \\
0.65\end{array}$ & $\begin{array}{l}1.43 \\
1.93\end{array}$ & \\
\hline Apparent absorption & & 0.01 & & & & & & \\
\hline Apparent excretion & & & 0.06 & 0.02 & 0.18 & 0.25 & 0.50 & $0-35$ \\
\hline \multicolumn{9}{|c|}{ Calculation of cholesterol contributed by loop $\ddagger$} \\
\hline & & & & $1-1 \mathrm{hr}$ & $1-1 \frac{1}{2} \mathrm{hr}$ & $1 \frac{1}{2}-2 \mathrm{hr}$ & $2-2 \frac{1}{2} \mathrm{hr}$ & $2 \mathrm{t}-3 \mathrm{hr}$ \\
\hline $\begin{array}{l}\text { a) Input of endogenous cholester } \\
\text { proximal intestine, } \mathrm{mg} / 50 \mathrm{c}\end{array}$ & $\begin{array}{l}\text { from } \\
h / \frac{1}{2} h r\end{array}$ & bile and & & 14.2 & 2.5 & 5.2 & 2.5 & 17.2 \\
\hline b) Absorption, $\%$ & & & & 60 & 70 & 71 & 66 & 56 \\
\hline c) Absorbed, $m g / 50 \mathrm{~cm} / \frac{1}{2} \mathrm{hr}$ & & & & 8.5 & 1.8 & 3.7 & 1.7 & 9.5 \\
\hline d) Not absorbed $(a-c), m g / 50 c$ & $n / \frac{1}{2} h r$ & & & 5.7 & 0.7 & 1.5 & 0.8 & 7.7 \\
\hline $\begin{array}{l}\text { e) Total loop output, i.e., outpu } \\
\text { lesterol from bile and proxi } \\
\text { tion of loop contribution no } \\
m g / 50 \mathrm{~cm} / \frac{1}{2} \mathrm{hr}\end{array}$ & $\begin{array}{l}\text { of end } \\
\text { nal inte } \\
\text { t absor }\end{array}$ & $\begin{array}{l}\text { ogenous cho- } \\
\text { stine plus frac- } \\
\text { bed, }\end{array}$ & & 9.7 & 5.8 & 4.4 & 7.7 & 16.3 \\
\hline $\begin{array}{l}\text { f) Fraction of output attributab } \\
\text { tion assuming no absorptio } \\
\text { lesterol }(e-d), m g / 5 \dot{0} \mathrm{~cm} / \frac{1}{2} \\
\text { contribution) }\end{array}$ & $\begin{array}{l}\text { e to loc } \\
\text { of con } \\
\text { hr }(\mathrm{mir}\end{array}$ & $\begin{array}{l}\text { p contribu- } \\
\text { tributed cho- } \\
\text { imal loop }\end{array}$ & & 4.0 & 5.1 & 2.9 & 6.9 & 8.6 \\
\hline $\begin{array}{l}\text { g) Fraction of output attributab } \\
\text { assuming absorption of con } \\
\text { one-half that of perfused ra } \\
f /\left(1-\frac{1}{2} b\right), m g / 50 \mathrm{~cm} / \frac{1}{2} \mathrm{hr} \\
\text { contribution) }\end{array}$ & $\begin{array}{l}\text { e to loc } \\
\text { ributec } \\
\text { dioactiv } \\
\text { naxima }\end{array}$ & $\begin{array}{l}\text { p contribution, } \\
\text { cholesterol is } \\
\text { e cholesterol } \\
\text { loop }\end{array}$ & & 5.7 & 7.8 & 4.5 & 10.3 & 12.0 \\
\hline
\end{tabular}

* Absorption is defined in text. When output from the text segment exceeds input, the sign of the calculation absorption has been reversed, and termed excretion.

† PEG = polyethylene glycol.

† Contribution of nonradioactive cholesterol occurring during absorption of radioactive cholesterol cannot be distinguished from exchange. 
lated as described) is termed "apparent endogenous cholesterol." In the upper collection site samples, it represents the sum of unabsorbed endogenous cholesterol from the input plus the unabsorbed portion of any cholesterol added by the intestinal segment to the perfusate. Thus there are two distinguishable sources of cholesterol in the output. Plotting of the ranked differences of input from output for cholesterol radioactivity, cholesterol mass, and apparent endogenous cholesterol showed essentially normally distributed values. The percentage of absorption for each of these figures was calculated either individually by subject and period and then averaged, or as the means of the differences of the averaged inputs and outputs for all subjects in each period. The results were the same irrespective of the method of calculation.

\section{Results}

I) Absorption of micellar components: ConCENTRATION CHANGES

Figure 1 is a composite graph showing the mean concentration changes of micellar components, with time, relative to those of the perfusate. The graph denotes changes occurring between the perfusion site and the upper sampling site, as well as those occurring in the test segment, and is thus complementary to balance data that consider only those events occurring between the sampling sites.

Net water movement was small and quite constant (graph A). The intermittent addition of endogenous bile to the perfusate was signaled by the sharp increases in bile salt radioactivity (B) occurring at the same time as moderate increases in cholesterol mass $(G)$ and decreases in cholesterol specific activity $(\mathrm{H})$. However, the constancy of bile salt mass (C) indicates that the mass of endogenous bile salts was small relative to that of the perfusate.

\section{A) Components other than cholesterol}

Monoglyceride was rapidly hydrolyzed to fatty acid (E), which in turn was readily absorbed. Monoglyceride radioactivity-referring to isotope present in both monoglyceride and liberated fatty acid-was readily absorbed between the perfusion site and the upper sampling site, and that which entered the test segment was completely absorbed (D).

Bile salts were not absorbed by the test segment
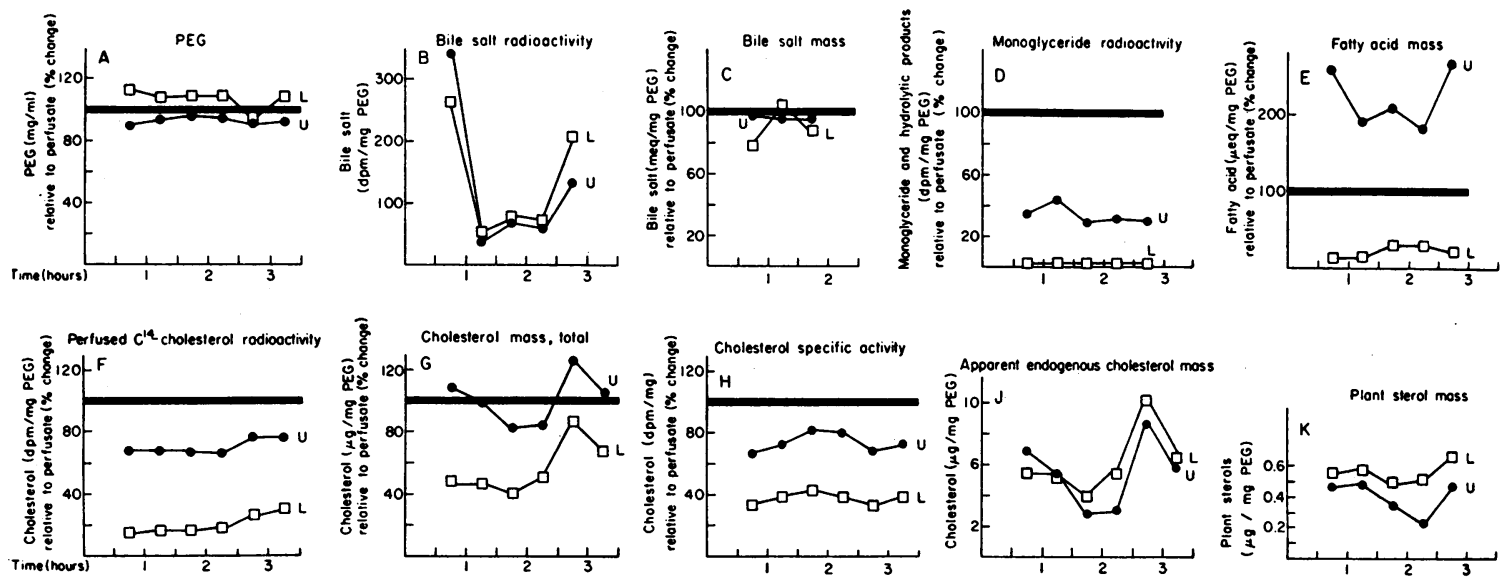

Fig. 1. Concentrations relative to polyethylene glycol (PEG); Continuous perfusion of bile saltMONOGLYCERIDE-MICELLAR CHOLESTEROL- ${ }^{14} \mathrm{C}$. Upper collection site samples, $\bullet, \mathrm{U}$; lower collection site samples, $\square, \mathrm{L}$; perfusate, solid black bar. Figures plotted in graphs $A$ to $C$ and $F$ to $J$ are the means of experiments $M C_{1}, M_{2}$, and $\mathrm{MC}_{3}$ for each collection period. Graphs $\mathrm{D}, \mathrm{E}$, and $\mathrm{K}$ show the changes of monoglyceride radioactivity, fatty acid mass, and plant sterol mass that would have been predicted to occur in these experiments, although the actual values are those of experiment $M$, in which the perfusate contained no cholesterol, but was otherwise identical; see text. The lower collection site values have been shifted to the left to correct for transit time (1 hour for $\mathrm{M}, \mathrm{MC}_{2}$, and $\mathrm{MC}_{3} ; 1$ hour for $M_{1}$ ).

The addition of bile to the perfusate is signaled by the following: a sharp rise in bile salt radioactivity, graph B; a rise in chemically determined cholesterol, graph G; a fall in cholesterol specific activity, graph $\mathrm{H}$; and an increase in the concentration of apparent endogenous cholesterol mass, graph $\mathrm{J}$. The increase in fatty acid concentration (graph E) is explained by rapid hydrolysis of the perfused 1-monoglyceride. The enrichment in plant sterol concentration indicates an endogenous contribution by the test segment. 
(B, C). Plant sterol, absent from the perfusate, was found in all intestinal samples, and its concentration increased during passage through the test segment $(\mathrm{K})$.

\section{B) Cholesterol}

Infused cholesterol radioactivity was absorbed between the perfusion site and the upper collection site $(F)$. The parallel curves for cholesterol radioactivity (F) and cholesterol mass (G) indicate that absorption by the test segment occurred at relatively constant rates throughout the perfusion and suggest that steady state conditions were obtained. The specific activity of infused cholesterol had decreased in upper collection site samples $(\mathrm{H})$ indicating either the addition of or exchange with endogenous cholesterol, or both. The parallel curves for cholesterol specific activity $(\mathrm{H})$ show that a decline in cholesterol specific activity occurred at a rather constant rate in the test segment throughout the perfusion.

The values plotted in Figure 1 are means of the values detailed in Table III. This Table includes experiments $\mathrm{M}$ and $\mathrm{S}$ in which cholesterol was absent from the perfusate. Nonetheless, cholesterol was present in both upper and lower collection site samples, although the concentrations observed were lower than those observed in the experiments with perfusions containing cholesterol. The results of the crossover experiments (not presented) were in agreement with those obtained in experiments $\mathrm{M}$ and $\mathrm{S}$.

\section{II) Balance Calculations}

From the concentrations relative to PEG (Figure 1) and the amount of PEG perfused through the test segment, the amount of a given component entering and leaving the $50-\mathrm{cm}$ segment (Table IV) and the percentage absorption (Figure 2) could be calculated, as detailed in Table II.

\section{A) Components other than cholesterol}

Bile salts were not absorbed, when balances were calculated for bile salt mass. Similarly, bile salt radioactivity balances also showed no mean absorption, despite large sampling errors (Figure 2, Table IV).

The monoglyceride was hydrolyzed rapidly, and balance calculations indicated that virtually

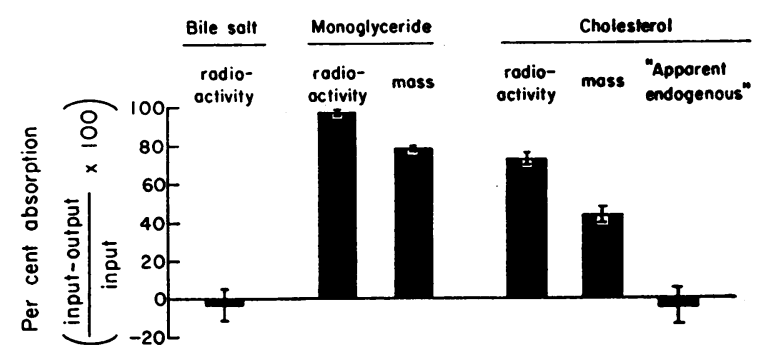

Fig. 2. Absorption of micellar components. The bars represent the mean and standard error calculated by averaging the per cent absorption for data pooled as described in the Methods.

all of the radioactivity (monoglyceride or liberated fatty acid or both) that entered the test segment was absorbed (Figure 2). The balance calculated on chemically determined total fatty acid (monoglyceride plus fatty acid) showed less absorption, largely due to the addition of endogenous fatty acid during passage through the test segment. In addition, some monoglyceride of extremely low specific activity was present in samples from the lower collection site; this was presumably formed by transesterification of the labeled monoglyceride to a 1,3-diglyceride followed by hydrolysis of the labeled fatty acid moiety. The fatty acid appearing in the upper collection site samples was derived from hydrolyzed monoglyceride, as it possessed nearly the same specific activity as the monoglyceride of the perfusate. In samples from $M \rightarrow S_{2}$, the specific activity of fatty acid (isolated by preparative thin layer chromatography) from four consecutive collection periods was (dpm per $\mu \mathrm{Eq}$ ) :250, 240, 236, and 210; the SA of the fatty acid of the perfusate monoglyceride was $278 \mathrm{dpm}$ per $\mu \mathrm{Eq}$.

In all patients, plant sterols were secreted by the perfused loop (Table II). All subjects had been on diets rich in plant sterols before their hospitalizations, but it was of interest that plant sterols were secreted in equal amounts during the second perfusion a day later.

\section{B) Cholesterol}

1) Continuous perfusions with micellar cholesterol- ${ }^{14} C$. The cholesterol present in the perfusate passing through the test. segment has three sources. The probable extent of absorption for material from each source can be inferred from Table IV and Figures 1 and 2. 


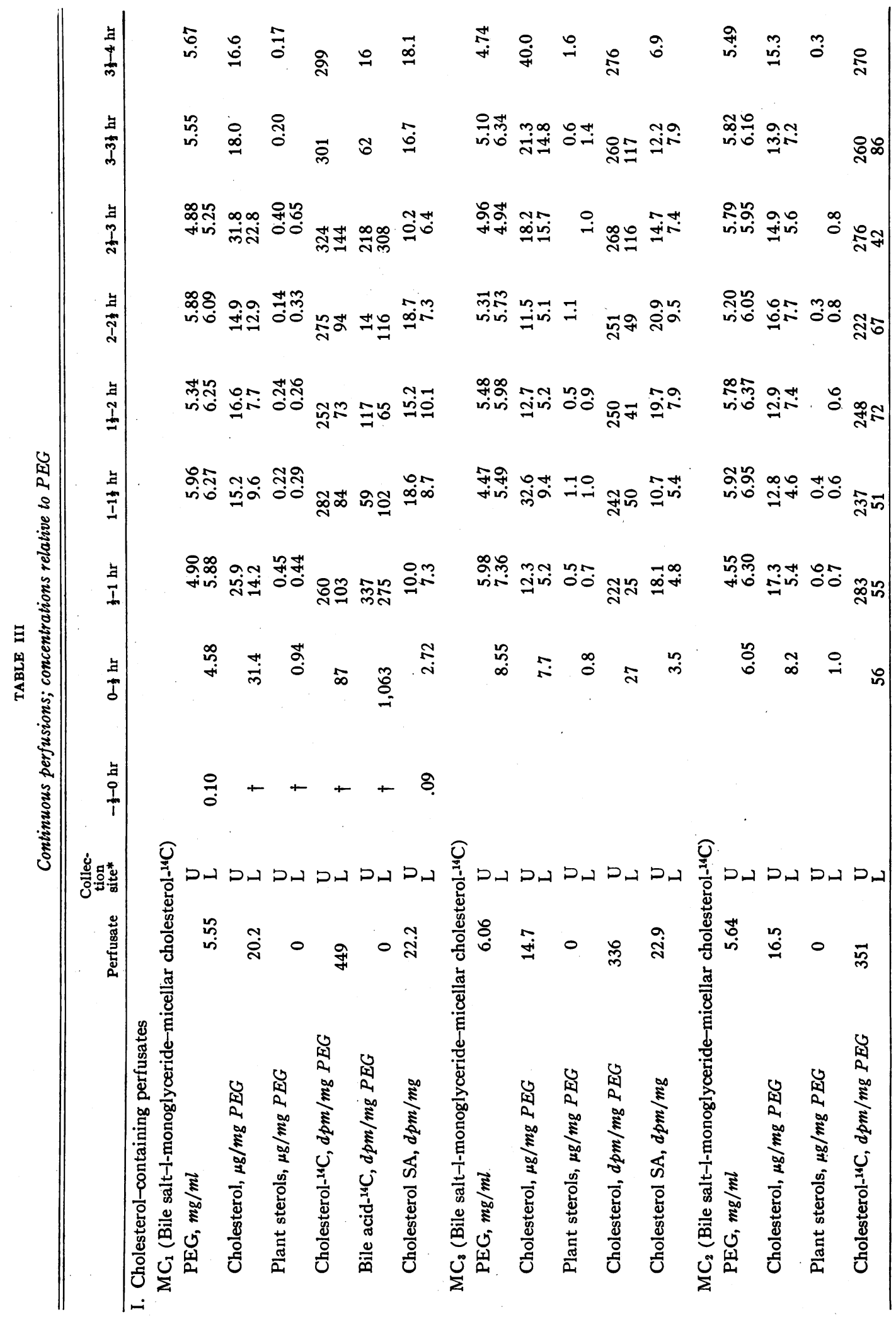




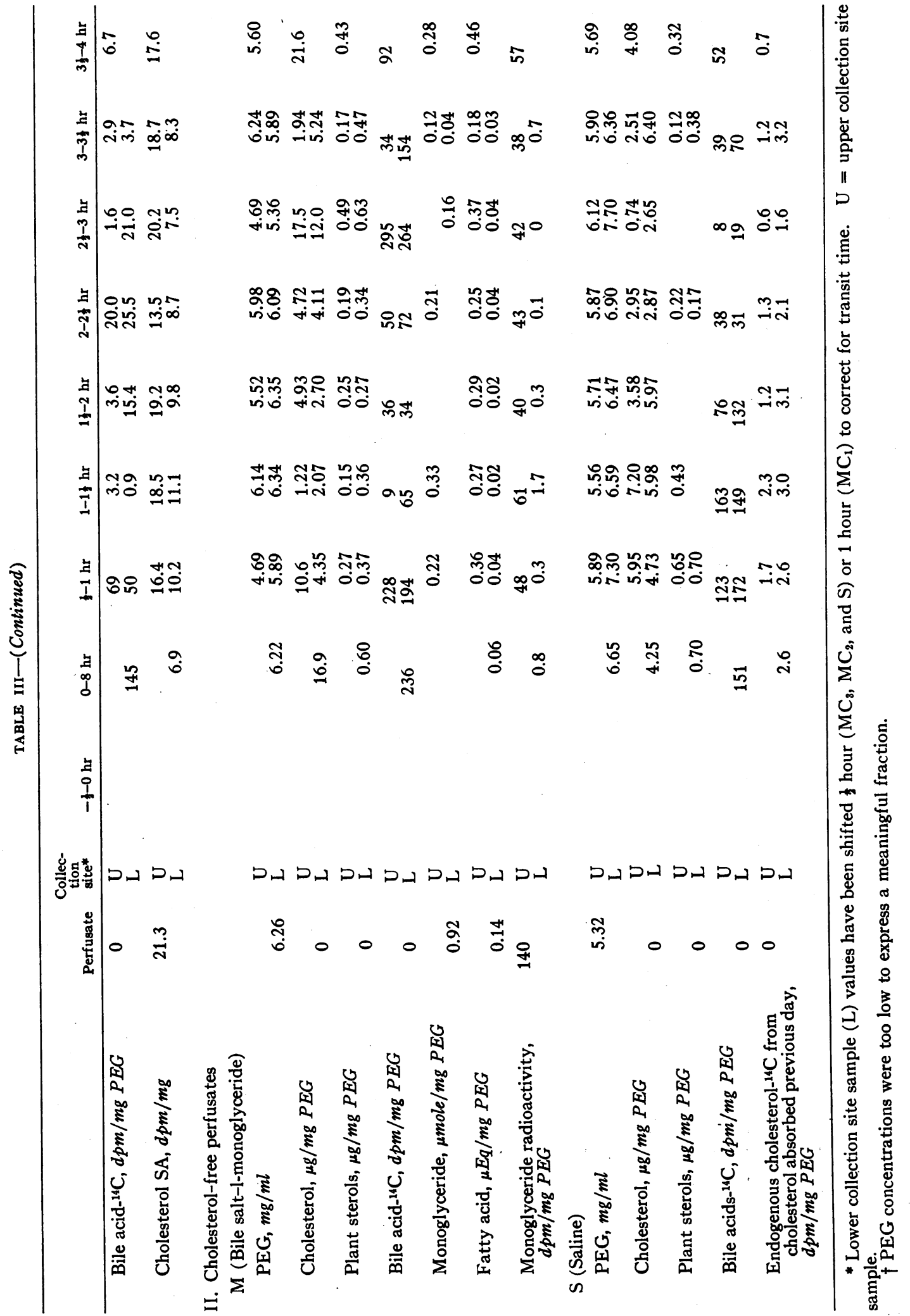


TABLE IV

Average half hourly balances for $50-\mathrm{cm}$ segment of jejunum

\begin{tabular}{|c|c|c|c|}
\hline \multirow[b]{2}{*}{ Component } & \multirow{2}{*}{$\begin{array}{l}\text { No. of } \\
\text { samples* }\end{array}$} & \multicolumn{2}{|c|}{ Mean $\pm \mathrm{SE}$} \\
\hline & & In $\dagger$ & Out \\
\hline $\begin{array}{l}\text { Bile salt radioactivity, } \\
\qquad d p m \times 10^{3}\end{array}$ & $38(7)$ & $100 \pm 12$ & $107 \pm 10$ \\
\hline $\begin{array}{l}\text { Monoglyceride radio- } \\
\text { activity, } d p m \times 10^{3}\end{array}$ & $7(2)$ & $44 \pm 6$ & $0.9 \pm 0.4$ \\
\hline $\begin{array}{l}\text { Fatty acid, free and } \\
\text { as monoglyceride, } \\
\text { mmole } / L\end{array}$ & $5(2)$ & $0.77 \pm 0.06$ & $0.16 \pm 0.02$ \\
\hline Plant sterols, $\mu g$ & $35(9)$ & $0.46 \pm 0.05$ & $0.75 \pm 0.06$ \\
\hline $\begin{array}{l}\text { Perfused choles- } \\
\text { terol-14 } \mathrm{C}, m g\end{array}$ & $15(3)$ & $11.9 \pm 0.3$ & $3.3 \pm 0.4$ \\
\hline $\begin{array}{l}\text { Total cholesterol } \\
\text { mass, } m g\end{array}$ & $15(3)$ & $17.4 \pm 1.5$ & $9.4 \pm 1.4$ \\
\hline $\begin{array}{l}\text { Apparent endogenous } \\
\text { cholesterol, } m g\end{array}$ & $15(3)$ & $6.1 \pm 1.0$ & $5.0 \pm 0.8$ \\
\hline $\begin{array}{l}\text { Endogenous loop } \\
\text { contribution of } \\
\text { cholesterol, } m g\end{array}$ & $15(3)$ & $\begin{array}{l}\text { Minimum }= \\
\text { Maximum }=\end{array}$ & $\begin{array}{l}4.1 \pm 0.5 \\
6.4 \pm 0.8\end{array}$ \\
\hline
\end{tabular}

* The number in parentheses is the number of perfusion experiments from which samples were used for balances. $\dagger$ In = passing upper sampling point; out = passing lower sampling point.

a) Biliary plus proximal intestinal sources. Together these constitute the apparent endogenous cholesterol passing the upper sampling point if one assumes equilibration with the radioactive perfused cholesterol before the sampling point is reached. The net balance for chemically determined cholesterol showed $46 \%$ absorption during passage through the segment. This is clearly a minimal absorption rate for unlabeled endogenous cholesterol passing the upper collection point, and since ultracentrifugal analyses of samples from the upper site showed that virtually all cholesterol (endogenous and exogenous) was micellar, it seems reasonable to assume that endogenous cholesterol passing the upper sampling point was absorbed by the $50-\mathrm{cm}$ jejunal segment at the same rate as the perfused radioactive cholesterol (i.e., $76 \%$ ).

b) Micellar cholesterol-14C. Cholesterol was well absorbed in the test segment. Although about one-third of the cholesterol from the lower sampling site was sedimentable and presumably no longer available for absorption, this represented only $8 \%$ of the perfused cholesterol- ${ }^{14} \mathrm{C}$.

c) Endogenous cholesterol contributed by the test segment. To calculate the contribution from this source to the cholesterol balance of the segment, we made several assumptions concerning the efficiency of absorption of cholesterol contributed by the segment. If such cholesterol were absorbed, it should not be absorbed so well as the perfused cholesterol since $a$ ) the secreted molecules are, on the average, only exposed to one-half the length of the test segment and $b$ ) the ultracentrifugal studies suggested that as the cholesterol passed through the intestinal loop a continuously increasing fraction of the molecules became unavailable for absorption. A minimal contribution may be calculated on the assumption that none of the added cholesterol is reabsorbed before passing the lower sampling point; a maximal figure may be calculated on the assumption of absorption at $50 \%$ of the efficiency for perfused micellar cholesterol. Such calculations for ex-

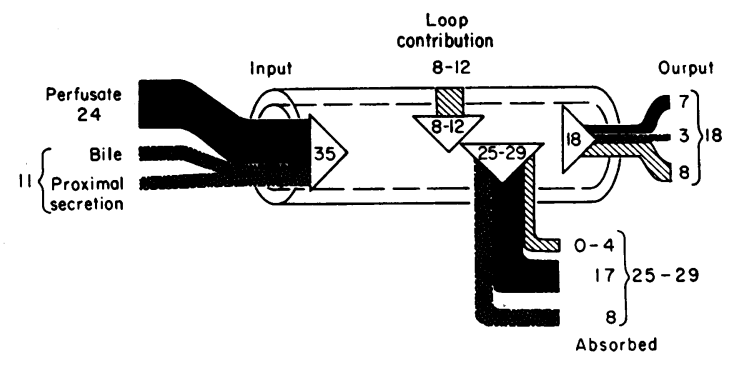

Fig. 3. Calculated cholesterol fluX in milligrams PER HOUR PER 50-CM TEST JEJUNAL SEGMENT FOR CONTINUOUS PERFUSION OF BILE SALT, 1-MONOGLYCERIDE, AND CHOLESTEROL- ${ }^{14} \mathrm{C}$ (eXPeriments $\mathrm{MC}_{1}, \mathrm{MC}_{2}$, AND $\mathrm{MC}_{3}$ ). Three sources of cholesterol are distinguished: endogenous cholesterol from bile and intestinal wall proximal to the test segment (dotted bars), perfused, micellar cholesterol (solid black bars), and endogenous cholesterol contributed by the test segment (hatched bars). The width of the bars is proportional to the cholesterol mass, and enables an estimate of the dilution of the specific activity of the cholesterol in the collection site samples, as well as that absorbed. These values are the results of calculations based on the assumptions 1 ) that endogenous cholesterol entering the test segment was absorbed at the same rate as the perfused micellar cholesterol, and 2) that the endogenous cholesterol that contributed to or exchanged with (or both) the luminal cholesterol was either not absorbed or, if absorbed, absorbed at a rate one-half that of the cholesterol from the other two sources. The contribution of endogenous cholesterol by the test segment occurred simultaneously with the absorption of radioactive cholesterol and may be considered to represent exchange. However, such exchange accounts for only 8 of the $17 \mathrm{mg}$ of absorbed radioactive cholesterol. 


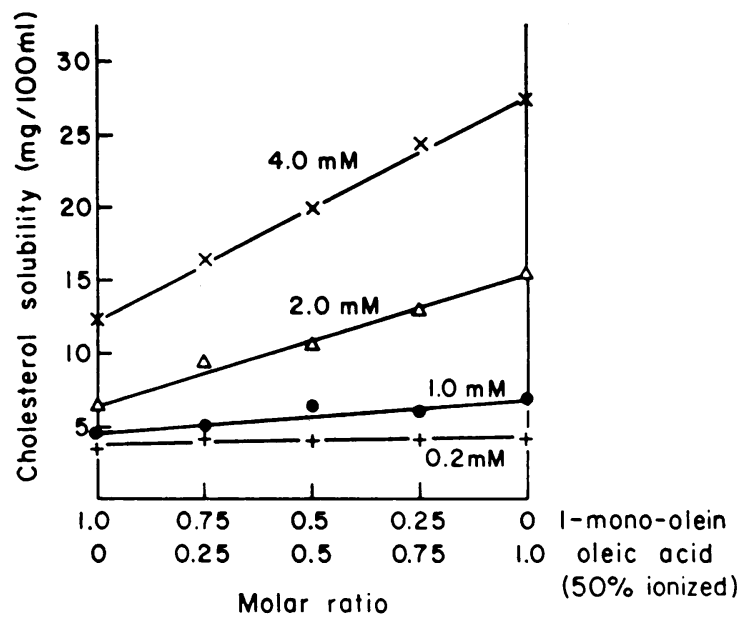

Fig. 4. EFFECT OF ADDED POLAR LIPID ON CHOLESTEROL SOLUBILITY IN MICELLAR BILE SALT SOLUTION. Oleic acid or glyceryl-1-mono-oleate was added singly or in mixtures, in amounts and molar ratios indicated, to $10 \mathrm{mM}$ sodium taurocholate-sodium taurodeoxycholate (that used in experiments $\mathrm{MC}_{1}, \mathrm{MC}_{2}$, and $\mathrm{MC}_{3}$ ) and phosphate buffer, $\mathrm{pH}$ 6.5. The total sodium ion concentration was 0.15 mole per L. At $\mathrm{pH} 6.5$, the fatty acid is about $50 \%$ ionized (28).

periment $\mathrm{MC}_{1}$ are detailed in the lower part of Table II. The calculated net mean fluxes of cholesterol are summarized in Figure 3.

2) Perfusion with cholesterol-free solutions. The balance data showed no over-all net absorption of endogenous cholesterol. Since cholesterol passing the upper sampling point was not labeled, no estimate could be made of the considerable absorption, secretion, or exchange or all of these that might have occurred despite no change in concentration. Although a number of perfusion periods showed apparent secretion of cholesterol by the test segment, sampling errors could not be ruled out, and the results of these experiments, although consistent with, did not prove cholesterol secretion by the test segment into the lumen.

\section{III) Physical state of Cholesterol}

\section{A) Solubility experiments}

The influence of fatty acid or monoglyceride or both on cholesterol solubility in bile salt solution was studied in model systems that were composed to simulate the conditions present during passage of the micellar cholesterol through the jejunal segment. It was considered desirable to vary $a$ ) the ratio of fatty acid to monoglyceride (in view of the marked hydrolysis that took place during perfusion), $b$ ) the amount of polar lipid present (in view of the rapid disappearance of polar lipid during perfusion), and $c$ ) the $\mathrm{pH}$ (since varying additions of pancreatic bicarbonate might have resulted in changing intraluminal $\mathrm{pH}$ ). The results of the solubility studies at $\mathrm{pH} 6.5$ are shown in Figure 4. These indicate that $a$ ) cholesterol solubility in micellar bile salt solution is low, $b$ ) cholesterol solubility in micellar bile salt solution increases markedly and proportionally to the amount of fatty acid or 1-monoglyceride or both added, $c$ ) the fatty acid-bile salt micelle solubilizes more cholesterol for a given molar composition than the monoglyceride-bile salt micelle, and $d$ ) the solubility effects of 1-monoglyceride and fatty acid are additive. The experiment was

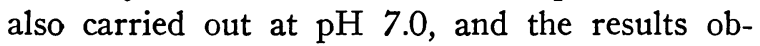

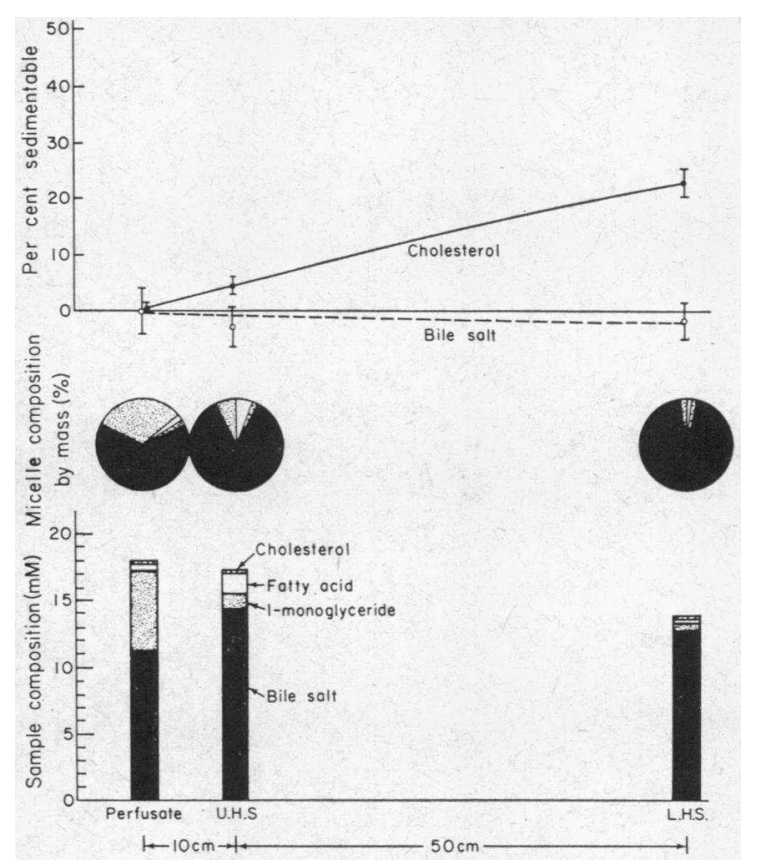

Fig. 5. MEAN PER CENT sedimentable ChOlesterol AND BILE SALT AFTER ULTRACENTRIFUGATION (TOP) OF THE PERFUSATES AND INTESTINAL CONTENT BEFORE AND AFTER PASSAGE THROUGH THE TEST SEgMENT. Three experiments; see Table IV. The mean composition of the perfusates, upper collection site samples (U.H.S.), and lower collection site samples (L.H.S.) is shown at the bottom. The composition of the micelles present (middle) was calculated with the assumptions that lipid is present only in micellar form and that the critical micellar concentration of the bile salt mixture employed is 3 mmoles per $\mathrm{L}$ (12). 


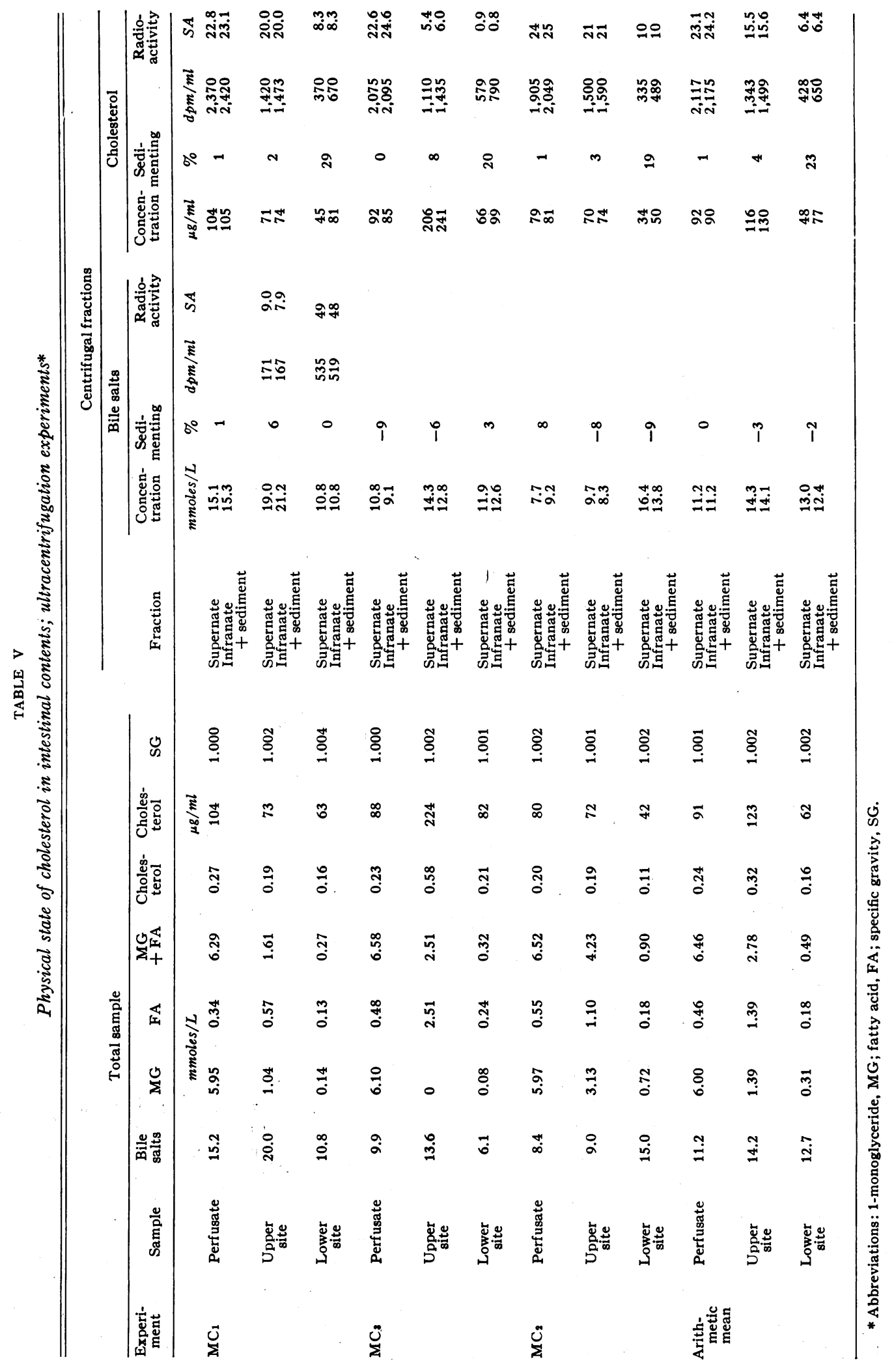


tained (not shown) indicated that there is little change in cholesterol solubility when fatty acid ionization is increased. Thus cholesterol solubility in bile salt solution is more influenced by the total amount of fatty acid and monoglyceride than its ratio and is not markedly influenced by $\mathrm{pH}$.

\section{B) Ultracentrifugation experiments}

Results are described in Table V and Figure 5. The disappearance of polar lipid from the micelle correlates with the appearance of sedimentable cholesterol. Although at least $50 \%$ of the monoglyceride mass had been absorbed by the upper collection site, cholesterol remained completely micellar in the samples obtained, for the concentration of cholesterol in these samples was less than the cholesterol solubility for that polar lipid concentration, as shown in vitro (Figure 4 ). The physical state of cholesterol in the sediment was not examined, but since the specific gravity of crystalline cholesterol is 1.058 , far greater than the observed specific gravity of the collection samples, the sediment was probably crystalline, resulting in its rapid sedimentation. The identical bile acid concentration in supernate and infranate indicates that sedimentation of components present in micellar form did not occur.

\section{Discussion}

These experiments show that intestinal perfusion with a micellar solution permits study of the absorption of water-insoluble substances in man under steady state conditions. They show further that cholesterol is readily absorbed from such a micellar solution, and that its absorption rate is independent of that of other micellar components. They confirm the necessity of polar lipid for the micellar solubilization of cholesterol and disclose the precipitation of cholesterol from solution, as the composition of the micelle is altered by the more rapid absorption of polar lipid. They thus provide a possible explanation for the relatively poor absorption of cholesterol in man $(31,32)$.

Independence of fat and bile salt absorption. The absence of bile salt absorption by the proximal jejunum confirms other perfusion studies in man $(11,33)$. Indeed, even passive diffusion of conjugated bile salts from the proximal jejunum (34) was insignificant in these experiments. The rapid hydrolysis of micellar 1-monoglyceride in the lumen agrees with in vitro studies (35). Since dietary triglyceride is absorbed as 2-monoglyceride and fatty acid $(36,37)$, and since micellar solutions of long chain 2-monoglyceride isomerize slowly to 1-monoglyceride (21), the rapid hydrolysis of 1-monoglyceride is probably not relevant to normal fat digestion and absorption. However, it is significant that infused monoglyceride and its digestion products were rapidly and completely absorbed. Thus human (11) and animal (38) data agree that 1) fat and bile salt absorption may occur independently and 2) the proximal intestine readily absorbs fat but absorbs conjugated bile salts poorly, if at all.

Rate of cholesterol absorption. Cholesterol presented in micellar form was well absorbed. The estimated rate of absorption was 25 to $29 \mathrm{mg}$ per hour per $50 \mathrm{~cm}$ jejunum. If absorption proceeded at this rate for a digestion period of 8 hours during the day over $200 \mathrm{~cm}$ of small intestine (about two-thirds of the total length), this would give an absorption of 800 to $930 \mathrm{mg}$ cholesterol per day. This is well above various recent estimates (31, $32,39,40$ ) of an upper limit of 300 to $500 \mathrm{mg}$ for absorption of dietary cholesterol but below certain earlier determined limits $(41,42)$. However, the present experiments were not designed and cannot be interpreted to assess this absorption maximum.

Cholesterol movements; absorption versus exchange. The cholesterol fluxes shown in Figure 3 assume that radioactive cholesterol molecules that disappeared from the lumen actually passed into the epithelial cells, i.e., that they were absorbed and not merely exchanged for unlabeled cholesterol molecules on the brush border. If exchange is defined as a one-for-one exchange of labeled for unlabeled molecules without net mass movement, then active absorption of radioactive cholesterol by one group of cells and simultaneous sloughing of other cells containing unlabeled cholesterol will give data interpreted as showing exchange for the test segment. The term "exchange" seems ambiguous since it refers to movements of individual molecules as well as those of pools of molecules that may not be in equilibrium. Notwithstanding, since mass disappearance was $60 \%$ of radioactivity disappearance, a majority of the decrease in radioactivity in these experiments cannot be explained by exchange; exchange as thus defined can account for only $8 \mathrm{mg}$ of the $17 \mathrm{mg}$ 
per hour of radioactive cholesterol absorbed by the $50-\mathrm{cm}$ test segment.

A more rigorous definition of exchange would be the mixing of two pools of different specific activity so that at equilibrium their specific activities were identical. During the 4 -hour perfusion of radioactive cholesterol there was no change in the magnitude of the decrease in specific activity that occurred with time as contents passed down the segment. Some alteration in the rate of decrease might have been expected if a substantial mass of cholesterol at the cell surface were continually equilibrating with the intestinal contents by simple exchange. This reasoning is correct only if exchange were limited to events at the cell border, and no further exchange with intracellular and lymph cholesterol took place.

In experiment $\mathrm{M}$, a cholesterol-free micellar solution was perfused. Cholesterol was present in all intestinal samples, and if the cholesterol entering the test segment is assumed to be absorbed at the same rate as that of radioactive cholesterol in experiments $\mathrm{MC}_{1}, \mathrm{MC}_{2}$, and $\mathrm{MC}_{3}$, the amount of cholesterol secreted by the loop can be calculated as described at the bottom of Table II. The value obtained was quite similar to that calculated for the experiments in which micellar cholesterol was perfused.

In summary, cholesterol was absorbed by, and in all probability, secreted by the test segment. Certainly, further work is necessary to determine more directly whether the intestinal wall makes a substantial contribution to endogenous cholesterol in the lumen. However, our experimental results, when considered together with the established requirement of bile for cholesterol absorption (43), suggest that bile salts mediated the continuous absorption of dietary and secreted endogenous cholesterol throughout the test segment. If the data were extrapolated to the entire small intestine, they would indicate a continuous movement of cholesterol from the intestinal lumen, presumably from sloughed mucosal cells, and the continuous absorption of this cholesterol by the more distal intestine. In this sense bile salts would mediate a continuous exchange of cholesterol between the mucosal cell and the intestinal lumen and, as a net result, an enterohepatic circulation of cholesterol.
Physical state of cholesterol in the lumen. The in vitro solubility experiments confirm and extend many previous demonstrations that the solubility of cholesterol in micellar bile salt solution is greatly enhanced by the addition of polar but water-insoluble lipid such as lecithin, monoglyceride, or fatty acid to the micelle $(4,12,17)$. Indeed, as the phase diagrams of Small, Bourgès, and Dervichian (44) show for the four component system, bile salt-polar lipid-cholesterol-water, polar lipid is virtually essential for cholesterol solubility in bile salt solution. The superiority of fatty acid over monoglyceride is interesting, since fatty acid predominates in the micellar phase of intestinal contents.

Recent monolayer penetration experiments (45) have provided data suggesting a molecular arrangement of the bile salt-monoglyceride micelle in which a spherical or cylindrical aggregate of monoglyceride or fatty acid or both is stabilized by adsorbed bile salt molecules. If this model of the bile salt-polar lipid micelle is correct, it means that the oily center of the bile salt micelle is provided by the nonpolar portion of the polar lipid; a molecular explanation is thus offered for the necessity of polar lipid for appreciable cholesterol solubilization.

Micellar solubilization may well be a rate-limiting factor in cholesterol absorption. The provision of necessary amounts of polar lipid could be the basis of the well-documented enhancement of cholesterol absorption by dietary triglyceride $(46,47)$. Our ultracentrifugation experiments indicated that cholesterol became sedimentable as polar lipid disappeared from the mixed micelles during passage through the test segment. Any complete description of the intraluminal phase of sterol absorption should probably consider a sediment phase as well as an oil and micellar phase.

The molecular mechanism by which micellar components enter the intestinal epithelial cells is not known and cannot be deduced from these experiments. The independent rates of absorption of cholesterol, and of monoglyceride and its digestion products, are consistent with molecular absorption (48), but cholesterol absorption may require an actual collision of micelles with cell membranes. Kinetic studies in vitro and in vivo will be needed to test this idea. 


\section{Acknowledgments}

We acknowledge the helpful advice of Dr. E. H. Ahrens, Jr., and Dr. Scott M. Grundy. Dr. Bruce Barron suggested the statistical techniques that were employed. Miss Joyce M. Lennane and Mrs. Mary Jane Russell gave skillful technical assistance. Miss Mary Nahon performed the gas-liquid chromatographic analyses of the bile acid samples.

\section{References}

1. Simmonds, W. J., E. Theodor, and A. F. Hofmann. Cholesterol absorption from the small intestine: perfusion studies with a micellar solution in man (abstract). Clin. Res. 1966, 14, 305.

2. Bergström, S., and B. Borgström. The intestinal absorption of fats in Progress in Chemistry of Fats and Other Lipids, R. T. Holman, W. O. Lundberg, and T. Malkin, Eds. London, Pergamon, 1955, vol. 3 , p. 352 .

3. Borgström, B. Studies on intestinal cholesterol absorption in the human. J. clin. Invest. 1960, 39, 809.

4. Hofmann, A. F., and B. Borgström. Physico-chemical state of lipids in intestinal content during their digestion and absorption. Fed. Proc. 1962, 21, 43.

5. Hofmann, A. F., and B. Borgström. The intraluminal phase of fat digestion in man: the lipid content of the micellar and oil phases of intestinal content obtained during fat digestion and absorption. J. clin. Invest. 1964, 43, 247.

6. Cooper, H., R. Levitan, J. S. Fordtran, and F. J. Ingelfinger. A method for studying absorption of water and solute from the human small intestine. Gastroenterology 1966, 50, 1.

7. Norman, A. Preparation of conjugated bile acids using mixed carboxylic acid anhydrides. Ark. Kem. $1955,8,331$.

8. Hofmann, A. F. The preparation of chenodeoxycholic acid and its glycine and taurine conjugates. Acta chem. scand. 1963, 17, 173.

9. Hofmann, A. F. Thin-layer chromatography of bile acids and their derivatives in New Biochemical Separations, A. T. James and L. J. Morris, Eds. London, Van Nostrand, 1964, p. 229.

10. Hofmann, A. F., and G. L. Paulson. Unpublished observations.

11. Borgström, B., G. Lundh, and A. Hofmann. The site of absorption of conjugated bile salts in man. Gastroenterology 1963, 45, 229.

12. Hofmann, A. F. The function of bile salts in fat absorption. I. The solvent properties of dilute micellar solutions of conjugated bile salts. Biochem. J. 1963, 89, 57.

13. Franzke, C., and F. Kretzschmann. Zur Darstellung von Monoglyceriden aus naturlichen Fetten. Fette Seifen Anstrichmittel 1963, 65, 276.
14. Miettinen, T. A., E. H. Ahrens, Jr., and S. M. Grundy. Quantitative isolation and gas-liquid chromatographic analysis of total dietary and fecal neutral steroids. J. Lipid Res. 1965, 6, 411.

15. Ekwall, P., K. Fontell, and A. Sten. Micelle formation in bile salt solutions in Gas/Liquid and Liquid/Liquid Interface, Proceedings of the Second International Congress on Surface Activity, J. H. Schulman, Ed. London, Butterworths, 1957, p. 357.

16. Laurent, T. C., and H. Persson. A study of micelles of sodium taurodeoxycholate in the ultracentrifuge. Biochim. biophys. Acta (Amst.) 1965, 106, 616.

17. Hofmann, A. F., and D. M. Small. Detergent properties of bile salts: correlation with physiological function. Ann. Rev. Med. 1967, in press.

18. Lindstedt, S. The turnover of cholic acid in man. Acta physiol. scand. 1957, 40, 1.

19. Hirsch, J., E. H. Ahrens, Jr., and D. H. Blankenhorn. Measurement of the human intestinal length in vivo and some causes of variation. Gastroenterology 1956, 31, 274.

20. Hydén, S. A turbidometric method for the determination of higher polyethylene glycols in biological materials. Ann. roy. agricul. Coll. Swed. 1955, 22, 139.

21. Hofmann, A. F. The behavior and solubility of monoglycerides in dilute, micellar bile-salt solution. Biochim. biophys. Acta (Amst.) 1963, 70, 306.

22. Desnuelle, P., and M. J. Constantin. Formation de glycérides partiels pendant la lipolyse des triglycérides dans l'intestin. Biochim. biophys. Acta (Amst.) 1952, 9, 531.

23. Grundy, S. M., E. H. Ahrens, Jr., and T. A. Miettinen. Quantitative isolation and gas liquid chromatographic analysis of total fecal bile acids. J. Lipid Res. 1965, 6, 397.

24. Bray, G. A. A simple efficient liquid scintillator for counting aqueous solutions in a liquid scintillation counter. Analyt. Biochem. 1960, 1, 279.

25. Neher, R. Steroid Chromatography, 2nd ed. Amsterdam, Elsevier, 1964, pp. 239-79.

26. Goldrick, B., and J. Hirsch. A technique for quantitative recovery of lipids from chromatoplates. J. Lipid Res. 1963, 4, 482.

27. Hofmann, A. F. Micellar solubilization of fatty acids and monoglycerides in bile salt solutions in The Enzymes of Lipid Metabolism, P. Desnuelle, Ed. London, Pergamon, 1961, pp. 158-71.

28. Hofmann, A. F. The function of bile salts in fat digestion: the behavior and solubility of saturated fatty acids in bile salt solution. Proceedings of the Fourth International Congress on Surface Activity, New York, Gordon and Breach, 1967, in press.

29. Croxton, F. E. Elementary Statistics with Applications in Medicine and the Biological Sciences. New York, Dover, 1953. 
30. Fisher, R. A., and F. Yates. Statistical Tables for Biological, Agricultural and Medical Research. New York, Hafner, 1957, pp. 86-87.

31. Wilson, J. D., and C. A. Lindsey, Jr. Studies on the influence of dietary cholesterol on cholesterol metabolism in the isotopic steady state in man. J. clin. Invest. 1965, 44, 1805.

32. Grundy, S. M., and E. H. Ahrens, Jr. An evaluation of the relative merits of two methods for measuring the balance of sterols in man: isotopic balance versus chromatographic analysis. J. clin. Invest. 1966, 45, 1503.

33. Linscheer, W. G., J. F. Patterson, E. W. Moore, R. J. Clermont, S. J. Robins, and T. C. Chalmers. Medium and long chain fat absorption in patients with cirrhosis. J. clin. Invest. 1966, 45, 1317.

34. Dietschy, J. M., H. S. Salomon, and M. D. Siperstein. Bile acid metabolism. I. Studies on the mechanisms of intestinal transport. J. clin. Invest. 1966, 45, 832.

35. Hofmann, A. F., and B. Borgström. Hydrolysis of long-chain monoglycerides in micellar solution by pancreatic lipase. Biochim. biophys. Acta (Amst.) 1963, 70, 317.

36. Mattson, F. H., and R. A. Volpenhein. The digestion and absorption of triglycerides. $\mathrm{J}$. biol. Chem. 1964, 239, 2772.

37. Kayden, H. J., J. R. Senior, and F. H. Mattson. Demonstration that 2-monoglycerides are incorporated intact into human lymph triglycerides (abstract). J. clin. Invest. 1966, 45, 1031.

38. Playoust, M. R., L. Lack, and I. M. Weiner. Effect of intestinal resection on bile salt absorption in dogs. Amer. J. Physiol. 1965, 208, 363.

39. Gould, R. G., and R. P. Cook. The metabolism of cholesterol and other sterols in the animal organ- ism in Cholesterol, R. P. Cook, Ed. New York, Academic Press, 1958, p. 237.

40. Kaplan, J. A., G. E. Cox, and C. B. Taylor. Cholesterol metabolism in man. Studies on absorption. Arch. Path. 1963, 76, 359.

41. Blomstrand, R., and E. H. Ahrens, Jr. Absorption of fats studied in a patient with chyluria. III. Cholesterol. J. biol. Chem. 1958, 233, 327.

42. Stanley, M. M., and S. H. Cheng. Cholesterol exchange in the gastrointestinal tract in normal and abnormal subjects. Gastroenterology 1956, 30, 62.

43. Siperstein, M. D., I. L. Chaikoff, and W. O. Reinhardt. $\mathrm{C}^{14}$-Cholesterol. V. Obligatory function of bile in intestinal absorption of cholesterol. J. biol. Chem. 1952, 198, 111.

44. Small, D. M., M. Bourgès, and D. G. Dervichian. Ternary and quaternary aqueous systems containing bile salt, lecithin, and cholesterol. $\mathrm{Na}$ ture (Lond.) 1966, 211, 816.

45. Dreher, K. D., J. H. Schulman, and A. F. Hofmann. Surface chemistry of the monoglyceride-bile salt system: its relationship to the function of bile salts in fat absorption. J. Colloid interfac. Sci. In press.

46. Pihl, A. The effect of dietary fat on the intestinal cholesterol absorption and on the cholesterol metabolism in the liver of rats. Acta physiol. scand. 1955, 34, 183.

47. Swell, L., D. F. Flick, H. Field, Jr., and C. R. Treadwell. Role of fat and fatty acid in absorption of dietary cholesterol. Amer. J. Physiol. 1955, 180, 124.

48. Hogben, C. A. M. Fat absorption: a transport problem. Gastroenterology 1966, 50, 51. 